\title{
A qualitative study examining the experience of primary care dentists in the detection and management of potentially malignant lesions. 1. Factors influencing detection
and the decision to refer
}

- Gives an idea of the types of screening practices undertaken in general dental practice and the attitudes of primary care dentists to oral cancer and its precursors.

- Gives an understanding of what factors influence dentists' decisions to refer early and potentially malignant disease.

- Readers will be able to learn where improvements could be made to future screening practices.

\author{
P. R. Brocklehurst, ${ }^{1}$ S. R. Baker ${ }^{2}$ and P. M. Speight ${ }^{3}$
}

Background and aims Many oral squamous cell carcinomas present as late stage disease and so the detection of early and pre-malignancy is considered to be of paramount importance. The majority of research examining primary care dentists' experience of the detection and management of early disease has been undertaken using questionnaires, with the inherent bias this introduces. The aim of this study was to use qualitative methods to develop a richer account of practitioners' views about screening and what factors influence the decision to refer a patient. Methods Semi-structured interviews were undertaken with eighteen dentists in Sheffield, transcribed and analysed using thematic analysis. Ten codes were identified according to the aims of the study and organized into four overarching themes. Results Although many dentists were screening regularly, some did not appear to be adopting a rigorous and systematic approach. A number of participants also placed more reliance on 'classical' presentations rather than the more varied presentation of potentially malignant lesions and were more influenced by the clinical history of the lesion rather than risk factors. Conclusion Overall, the present research suggests that for some dentists, more rigour is required when examining for early disease.

\section{INTRODUCTION}

The Department of Health in England have recently placed greater emphasis on the early detection of disease in their Cancer Reform Strategy (2007). ${ }^{1}$ This is particularly relevant for the diagnosis and management of oral squamous cell carcinomas (OSCC), which tend to present as late stage disease with regional lymph node metastases. ${ }^{2}$ A recent Health Technology Assessment ${ }^{3}$ concluded that opportunistic screening by primary care dentists (PCDs) of high risk patients may be a cost-effective strategy to reduce these delays. However, while a

Specialist Registrar (Mersey Deanery)/Honorary Lecturer, School of Dentistry, The University of Manchester, Higher Cambridge Street, Manchester, M15 $6 \mathrm{FH} ;{ }^{2}$ Senior Lecturer in Psychology, Oral Health and Development, ${ }^{3 *}$ Dean and Professor of Oral Pathology, School of Clinical Dentistry, University of Sheffield, Claremont Crescent, Sheffield, S10 2TA

${ }^{*}$ Correspondence to: Professor Paul M. Speight Email:p.speight@sheffield.ac.uk

\section{Online article number E3}

Refereed Paper - accepted 15 July 2009

DOI: $10.1038 /$ sj.bdj.2010.54

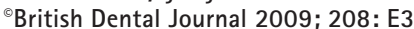

number of studies have demonstrated that PCDs do routinely examine the soft tissues, ${ }^{4-6}$ relatively few studies have examined in detail what factors influence the attitudes of PCDs towards screening and their decision to refer.

Understanding the attitudes of PCDs towards screening and the management of the disease is important given that the diagnosis can be difficult. ${ }^{7,8}$ However, given that the majority of the studies highlighted above have used questionnaires to determine the views of PCDs, the aim of this study was to use qualitative methodology in order to record the detail of dentists' views.

Qualitative methods have been increasingly used in healthcare research, ${ }^{9}$ dentistry and in studies of patient's experience of oral cancer. ${ }^{10}$ As a research paradigm, the aim is to elicit the unique meaning that people attach to their experiences, ${ }^{11}$ rather than measuring behaviour against questions set a priori. ${ }^{12}$ As such, it is a particularly useful approach to apply in areas where the available literature is relatively sparse, ${ }^{13}$ as new themes are allowed to emerge from the data producing a richer account of behaviour. ${ }^{11}$

Semi-structured interviews are the most common of the qualitative techniques as they allow participants to talk candidly about their experiences, while allowing the interviewer to guide the interviewee towards pertinent areas for discussion..$^{11,12}$ Among the many approaches that are available for subsequent analysis, thematic analysis is particularly useful as it is not tied to any specific philosophical assumptions about the nature of knowledge, which means that primacy is given to the data rather than the method of interpretation. ${ }^{14}$

\section{METHODOLOGY}

\section{Participants}

After approval by the South Sheffield Research Ethics Committee [LREC reference number 06/Q2305/28], a letter of invitation was sent out to all the dental practices in Sheffield, South Yorkshire. PCDs who 
Table 1 The complete coding frame for the thematic analysis

\begin{tabular}{|c|c|c|c|}
\hline Theme & $\begin{array}{l}\text { Code } \\
\text { number }\end{array}$ & Code & Description of the codes \\
\hline \multirow{4}{*}{$\begin{array}{l}\text { Factors influencing } \\
\text { the screen }\end{array}$} & 1 & Proactive in screening & Whether the dentist screens regularly and is proactive in their attitudes towards screening \\
\hline & 2 & $\begin{array}{l}\text { Incidence of potentially } \\
\text { malignant lesions }\end{array}$ & Comments of the number of potentially malignant lesions that are seen by the dentist \\
\hline & 3 & $\begin{array}{l}\text { Awareness of cancer referral } \\
\text { guidelines }\end{array}$ & $\begin{array}{l}\text { Awareness of any guidelines about the oral mucosal screening pathway in the } \\
\text { new contract }\end{array}$ \\
\hline & 4 & Mechanics of the examination & Detail of what the dentist is looking for, how they screen and what they write in the notes \\
\hline \multirow[t]{3}{*}{ Lesion factors } & 5 & Physical characteristics of the lesion & The physical factors that raise the dentist's index of suspicion \\
\hline & 6 & History of the lesion & Dynamic changes to the lesion and its history of prompt referral \\
\hline & 7 & Abnormality as a reason to refer & $\begin{array}{l}\text { Lesions are described as mucosa that is not normal rather than having a specific } \\
\text { provisional diagnosis }\end{array}$ \\
\hline \multirow[t]{3}{*}{ Patient factors } & 8 & $\begin{array}{l}\text { Experience of health and disease } \\
\text { in diagnosis }\end{array}$ & Comments on the importance of knowing your patients and their regular attendance \\
\hline & 9 & What the patient brings? & How the patient's response can change the decision to refer \\
\hline & 10 & Patients' risk factors & Comments on what patient factors would raise the dentist's index of suspicion \\
\hline PCD factors & 8 & $\begin{array}{l}\text { Experience of health and disease } \\
\text { in diagnosis }\end{array}$ & $\begin{array}{l}\text { Clinical experience as a factor in determining whether the mucosa is healthy } \\
\text { or diseased }\end{array}$ \\
\hline \multirow{5}{*}{$\begin{array}{l}\text { Outcome of the } \\
\text { clinical encounter }\end{array}$} & $11^{*}$ & What's told to the patient & Describes the information that is given to the patient \\
\hline & $12^{*}$ & Patient's response & The patient's response to being told that a potentially malignant lesion has been found \\
\hline & $13^{*}$ & Health promotion to the patient & The advice given to the patient about the known risk factors of malignant disease \\
\hline & $14^{*}$ & Management within primary care & $\begin{array}{l}\text { Comments on the management of potentially malignant lesions in practice before a } \\
\text { referral is made }\end{array}$ \\
\hline & $15^{*}$ & Mechanics of referral and feedback & $\begin{array}{l}\text { Practical aspects of the referral process detailing how dentists refer and who they send } \\
\text { their referrals to }\end{array}$ \\
\hline \multirow{3}{*}{$\begin{array}{l}\text { Role of general } \\
\text { medical practitioners } \\
\text { (GMPs) in the referral } \\
\text { of PMLs }\end{array}$} & $16^{\dagger}$ & Relationship with GMPs & The perception of the dentist's relationship with doctors \\
\hline & $17^{+}$ & $\begin{array}{l}\text { Why patients go to GMP } \\
\text { compared to PCDs? }\end{array}$ & The perception from dentists as to why patients prefer to see doctors \\
\hline & $18^{+}$ & GMPs' ability/management & $\begin{array}{l}\text { The perception of dentists about the management of potentially malignant } \\
\text { lesions by doctors }\end{array}$ \\
\hline \multirow{5}{*}{$\begin{array}{l}\text { Relationships with } \\
\text { secondary care }\end{array}$} & $19^{\ddagger}$ & Attitudes towards referral process & The experience of secondary care from the perspective of the dentist and the patient \\
\hline & $20^{+}$ & Views on the way forward & Comments detailing what would improve the current referral system \\
\hline & $21^{\varsigma}$ & Views of other PCDs & Views of others dentists' knowledge and practice \\
\hline & $22^{\S}$ & Case history & Examples of experience of potentially malignant lesions and malignancy \\
\hline & $23^{\S}$ & Management of lichen planus & How lichen planus is managed at the practice \\
\hline
\end{tabular}

responded were contacted by telephone to arrange an interview at their practice.

\section{Procedure}

A set of opening questions was developed for the semi-structured interviews from existing research on delays in oral cancer presentation $^{7,15-21}$ and the results of an earlier pilot study by the same authors. ${ }^{22}$ In accordance with Carter and Henderson, ${ }^{23}$ these were open-ended questions and investigated the following areas: experience of soft tissue lesion referrals; factors used in formulating the decision to refer; attitudes to secondary care; and attitudes to other health professionals.

The interview was recorded on a Sony Digital Recorder, ICD-P110 and the audiofiles transcribed verbatim by one researcher [PRB] into MS Word documents for thematic analysis to develop a coding frame. ${ }^{14}$ Two of the researchers immersed themselves in the data by initially reading and re-reading the transcriptions. Initial codes were then generated from three transcripts selected at random by each of the two researchers
[PRB and SRB] independently. The highlighted phrases were then compared and once agreement had been reached the coding frame was formed. Further transcripts were then analysed and highlighted phrases copied into separate documents according to their codes to facilitate further analysis by all three authors. It was determined in advance that the interviews would continue until saturation had been reached. ${ }^{11}$ This was assessed by one of the authors [PRB] when no new information was generated from the analyses. 
Overarching themes were developed from the coded transcripts by organising them into clusters based on the similarity of their meaning ${ }^{14}$ by all three authors to facilitate triangulation. ${ }^{9}$ These were then checked against the coded extracts and the raw data to ensure that they formed a coherent pattern and were representative of what the participants were trying to convey. Specific examples were selected to create clear definitions for the coding frame and representative quotes of each theme are given in the results, with any associated hesitations and repetitions removed for clarity. In accordance with qualitative methodology, the views of the researchers interpreting the text are given below to ensure transparency. ${ }^{12}$

\section{Reflexivity}

The three researchers were a Professor of Oral Pathology (PMS), a Chartered Health Psychologist (SRB) and a General Dental Practitioner (PRB). PMS has reported widely on the subject of screening for oral cancer and pre-malignant lesions (PMLs) $^{3,24}$ and his hypothesis was that PCDs were screening but were not using the appropriate cues when referring PMLs. SRB has experience both in qualitative and quantitative techniques, ${ }^{25}$ but held no previous view on the nature of screening and behaviour of PCDs in the area. PRB's view was that screening was not undertaken routinely by all PCDs, but that the incidence of PMLs among regular attenders in practice was low.

\section{RESULTS}

\section{Demographics}

Out of the 42 questionnaires that were returned by the PCDs, 18 were interviewed. The mean age of the participants was 47 years (range 33-61; SD = 8.45) and 16 were men $(88.8 \%)$. With regard to professional experience, the mean year of qualifying was 1983 (range 1973-1999; $\mathrm{SD}=9.33$ ), 38.9\% had additional qualifications and $77.8 \%$ belonged to professional groups. The majority of the PCDs described their practices as being mixed (64.7\%), with only $23.5 \%$ and $11.8 \%$ describing their practices as totally dedicated to either the NHS or private dentistry respectively.

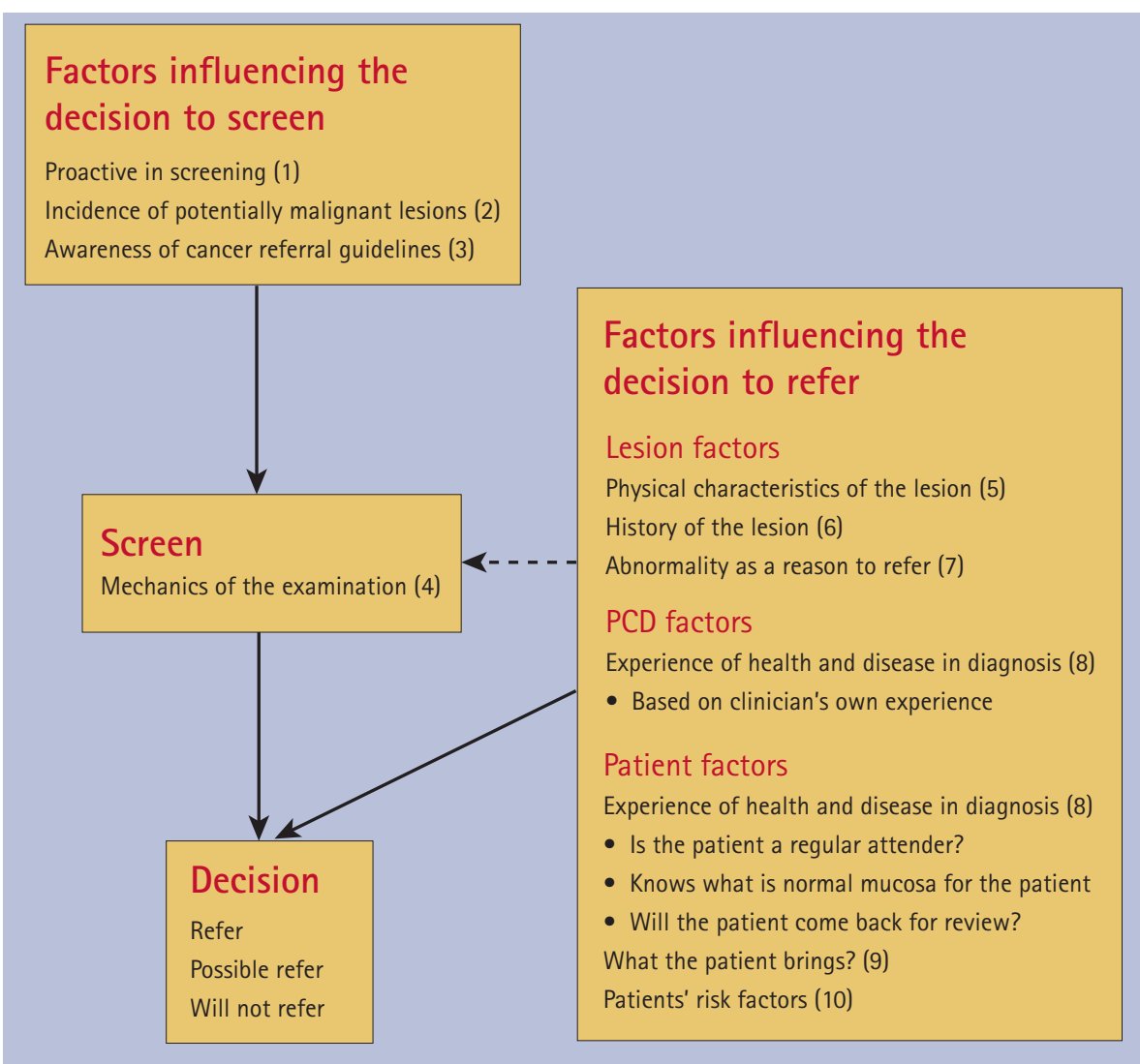

Fig. 1 The inter-relationship between the lesion, the primary care dentist and the patient when screening for and referring potentially malignant lesions

\section{Thematic analysis}

The thematic analysis produced a coding frame with 23 codes organised into seven overarching themes. This paper reports on the first ten codes, which were divided into four main themes relating to the detection and referral of PMLs. Code 8 contained material that was considered to apply to two of these themes and so is included under both (Table 1). Codes 11 to 15 describe the outcome of the examination and are reported in Brocklehurst et al. ${ }^{26}$ and codes 16 to 20 describe the relationship between PCDs, general medical practitioners (GMPs) and secondary care. ${ }^{27}$ Codes 21 to 23 were considered by the authors to fall outside of the aim of this study and so are not reported. The arrangement of the codes into superordinate themes by the authors is given in Figure 1 and each example that is given in the text is prefixed with the code of the participant and the line number where it appears in the transcript of the interview.

\section{Theme 1: factors influencing the screen}

Code 1: proactive in screening

A dentist's attitude to screening is considered to be one of the important factors in detecting the early stages of malignancy ${ }^{7,19,21}$ and while some PCDs in this study were proactive, there was a lot of recorded variation.

68.1 '...every examination includes a soft tissue exam... ... whether it is a routine check-up or whether they are coming in pain or discomfort...'

88.27 '...I think I probably just sub-consciously do a soft tissue...screening...as I am looking round at everything...'

\section{Code 2 : incidence of potentially} malignant lesions

This lack of rigour among some PCDs may be influenced by the perceived incidence of pre-malignant and malignant disease, which the majority of the participants described as low.

46.47 '...I've got a few...I can't say I've got a lot...because you know........you don't see a lot...'

Code 3: awareness of cancer referral guidelines

There was also a general lack of awareness of any developments in the oral health assessment to include a soft tissue screen. 
58.544 '...we try to anticipate what would be in the new contract... whether it be mucosal screening...or occlusion status or...whatever...but certainly with the advent of the new contract...I've got no information from the PCT...'

77.621 '...I am not aware of anything... from the PCT on that...'

Although there were a number who expressed that this might be helpful:

66.564 '...but it would be nice to have one and then...if anything...if the patient does come down with anything...we would have followed the protocol...'

Code 4: mechanics of the examination Variation in behaviour was also seen in the mechanics of the examination, with some dentists undertaking a formalised screen routinely for every patient, while others were less thorough.

41.578 '...no...it's just everybody...it's everybody and then you never forget and you do the same exam for everybody...'

88.6 '...if the patient's come in and I do a general check up and I try my best to have a look around all the soft tissues... given that...the truth is that it can be quite difficult to see some of the areas that are involved...'

Previous research has shown that some PCDs also lack confidence in detecting oral cancer ${ }^{4,5}$ and although this was not found here, there were a number of comments that an extra-oral examination was beyond the dentists' expertise.

51.10 '...you know...you see underneath the tongue...the tongue...cheeks...inside the lips... a rough scan of the outside... a little bit out of our field...'

\section{Theme 2: lesion factors}

Code 5: physical characteristics of the lesion

The majority of dentists described the common presentations of PML when asked what aspects of a lesion would warrant concern, but also included other important factors like location.

10.133 '...well there is the ulceration... indurated borders...fixed lesion...red... speckled...floor of the mouth...side of the mouth...'
66.129 '...probably if it is just a white patch it is just a white patch...but if it is a speckled white patch...asymmetric on the floor of the mouth then I would presume... again that would go straight off...'

68.39 '...redness...bleeding...ulceration... generally non-painful...maybe things that the patients haven't noticed themselves... and erythematous lesions...ill-defined margins...this type of thing...would start ringing bells...immediately...'

77.785 '...I suppose unexplained ulceration...redness...mixed lesions...and I suppose I would look at the hardening of the tissues...fixation... ...lymph node involvement... ...I don't think symptomatic...or asymptomatic doesn't make a difference to me...'

However, a number of PCDs framed what they were looking for in 'textbook' or 'classical' terms, which suggests for these dentists, they may not fully appreciate the range of appearances of PMLs ${ }^{28}$ and instead are looking for signs of advanced disease.

18.579 '...an ulcer with a rolled edge... I would know that instantly...that would be urgent...'

51.133 '...not just the fact that it is an ulcer...either...it's the shape...the edges of the ulcer...just the general appearance of it...you can tell an aphthous ulcer from a malignant ulcer...'

88.54 '...a typically textbook...squamous cell carcinoma...that had got...you know... the rolled edges and all the rest of it...'

\section{Code 6: history of the lesion}

Another important contributory factor expressed by a number of dentists related to the history of the lesion.

70.113 '...particularly history of something changed...something which can't be seen on the other side of the mouth... couldn't be seen as a normal for them... there is no obvious cause for it...'

Code 7: abnormality as a reason to refer As highlighted by the previous comment, another key issue was whether the mucosa looked normal or not.

70.117 '...exclude all the normal things... but something that you can't readily account for...in the normal scenarios...'

\section{Theme 3: patient factors}

Code 8: experience of health and disease in diagnosis

Another code that appeared to be related to the PCDs' experience of health was their experience of their patients, ie determining what was normal mucosa for the individual patient.

45.446 '...I think it is very useful...I mean we are just looking...I think it is very useful...knowing people you are seeing...'

41.490 '...and obviously as a dentist... you probably have...more...regular contact with patients... twice a year or whatever... so you are in a better position to check the... the lesion...'

Code 9: what the patient brings?

In addition to the factors associated with the lesion, PCDs also stated that factors associated with the patient can influence their referral. For example, patients' anxiety may modify the decision to refer.

77.400 '...there have been a couple of patients...one has...pushed through...I will say that... ...call them the worried well...'

Gender differences were also raised by two PCDs, where exposure to screening programmes for breast and cervical cancer was reasoned to make them more aware of the public health message about early detection.

37.426 '...if it is women...they are usually more clued up...because of things like smear tests... ....and cellular change... ... and you tend...often are a little bit more receptive...'

Code 10: patients' risk factors

Similar to other areas highlighted above, there was a wide variation between the PCDs. For some, risk factors were considered very important:

10.68 '...I find myself being a little more...shall we say...tentative on people of a certain age where they are heavy smokers and drinkers...'

59.62 '...starting from the medical history...you know the alarm bells start ringing if they are a heavy smoker...'

However, there were a few PCDs who suggested that risk factors did not play a part in their decision making process and 
that it was much more determined by factors associated with the lesion.

70.79 '...I know there are associated risk factors...but I don't look for them particularly... ...we can have trouble without the risk factors...so it is not a particularly reliable way to decide whether to refer someone or not...'

88.304 '...the fact that they may be a heavy smoker...or they maybe a heavy drinker...wouldn't...would be a bit too late really...in my mind... ...you've already got the lesion...'

\section{Theme 4: PCD factors}

Code 8: experience of health and disease in diagnosis

Despite the suggested lack of prevalence of PMLs or malignancy at their practices, a number of PCDs suggested they used their clinical experience of the disease to differentiate between healthy and diseased tissue. However, again there was a tendency to describe these in 'classical' terms.

45.100 '...I think I have only actually picked up...I think...hopefully seen...or found...two oral cancers...both of which were screamingly obvious to me...'

18.61 :...ulceration...white and red lesions basically...that's about it...I know what oral cancer looks like...seen it...'

46.452 '...I don't know...the ones...you don't see an awful lot of the things that you classically see in the lectures...'

In addition, in similarity to the comments on patient attendance, a number of PCDs used their idea of 'health' for a particular patient to rule out disease.

46.310 '...abnormal mucosa really...I mean we get to know what's normal and what's not...'

\section{DISCUSSION}

A number of studies suggest that PCDs do regularly screen, ${ }^{4,6}$ but the majority have used questionnaires to record behaviour, with the inherent bias this introduces. By undertaking a qualitative study, a richer account of PCDs' attitudes is obtained and appears to highlight a lack of rigour among some dentists, which has been identified in earlier research. ${ }^{29}$ This is a cause for concern, given that the sample of dentists were self-selecting and so arguably represents those who are prepared to be scrutinised.

It is reassuring to see that the majority of the dentists interviewed did identify the common presentations of PMLs. The complexity of the judgement task often produces greater individual variation ${ }^{30}$ and one of the great difficulties with PMLs is the number of clinical presentations that the disease can take. ${ }^{8,28}$ This has already been reported in the context of PMLs ${ }^{5,7}$ and has been confirmed by the present study.

In our previous study, ${ }^{22}$ we showed that the cues relating to frank malignancy ('fixation', 'induration') were more likely to prompt referral than cues relating to PMLs. Overall, the results of the present study reinforce the findings from earlier research ${ }^{4,5,29}$ and suggest that many PCDs are giving due consideration to early signs in accordance with the guidelines of the National Institute for Health and Clinical Excellence (2005). ${ }^{31}$ However, it is surprising that this important source was not quoted once by any of the participants and it is worrying that some placed greater emphasis upon classical or textbook presentations of malignancy rather than PMLs, suggesting that further training is still necessary to promote a systematic and rigorous approach early detection of PMLs. ${ }^{7}$

Reibel $^{8}$ argues that there are three major problems in detecting PMLs and their potential for malignant transformation: the diagnoses can be subjective; not all lesions exhibiting dysplasia will eventually become malignant and some may even regress; and OSCC can develop within apparently 'normal' mucosa. ${ }^{32}$ Earlier work has suggested that erythroplakia is not consistently identified as a lesion that warrants concern, ${ }^{4,5,22}$ even though this form of PML has fewer differential diagnoses when compared to other types of lesion and is considered to be an important sign of malignant change. ${ }^{2}$ However, the results of this study would suggest that many of the PCDs are giving due concern to erythroplakia and increase their index of suspicion accordingly should this or a speckled presentation be found.

In Greenwood and Lowry's questionnaire-based study, ${ }^{29}$ the numbers of PCDs that identified smoking, alcohol and habits as risk factors for potentially malignant and malignant disease was 93.7\%, 85.3\% and $60.8 \%$ respectively. This was also found by Carter and 0 gden ${ }^{4}$ and suggests that dentists recognise the impact that risk factors play in carcinogenesis. However, similar to a number of other areas highlighted above, there is often a gap between stated intentions and behaviour which questionnaire studies do not record. In this study, the impact of risk factors on the decision to refer and the formal recording of such habits was again considerably varied and is not dissimilar to earlier research, ${ }^{6}$ particularly in respect of alcohol. ${ }^{5}$ There were even a few PCDs who suggested that risk factors did not play a part in their decision making process and that the decision to refer was determined more by factors associated with the lesion, or by its clinical history.

In addition, further factors contributed to the decision to refer, including the PCDs' experience of healthy mucosa, their patients' attitudes and attendance patterns, and the dentists' previous experience of malignancy. Of particular interest is how many PCDs would use their understanding of what normal mucosa should look like for a particular patient to determine whether the tissue was abnormal, rather than making an explicit diagnosis. To a large extent this is not unexpected given that a definitive diagnosis can only be confirmed by histological analysis, but a diagnosis by exclusion based on idea of 'health' may explain why some PCDs are influenced by their apparent 'knowledge' of their patients' mucosa.

\section{CONCLUSIONS}

While screening for PMLs does appear to be undertaken, some PCDs do not appear to be adopting a rigorous approach. Equally, many but not all PCDs are examining their patients for PMLs and accounting for risk factors in their decision to refer. Factors associated with the lesion and its clinical history were considered to be important in the decision to refer, but other factors identified were PCDs' experience of healthy mucosa, their patients' attitudes and attendance patterns, and the dentists' previous experience of malignancy. Overall, the present research reveals that a systematic approach is still not being adopted by all PCDs to the screening and diagnosis of PMLs. 
1. Department of Health. Cancer reform strategy. London: The Department of Health, 2007.

2. Mashberg A. Diagnosis of early oral and oropharyngeal squamous carcinoma: obstacles and their amelioration. Oral Oncol 2000; 36: 253-255.

3. Speight P M, Palmer S, Moles D R et al. The cost-effectiveness of screening for oral cancer in primary care. Health Technol Assess 2006: 10(14): 1-144.

4. Carter L M, Ogden G R. Oral cancer awareness of general medical and general dental practitioners. Br Dent J 2007; 203: E10

5. MacPherson L M, McCann M F, Gibson J, Binnie V I, Stephen K W. The role of primary healthcare professionals in oral cancer prevention and detection. Br Dent J 2003; 195: 277-281.

6. Warnakulasuriya K A A S, Johnson N W. Dentists and oral cancer prevention in the UK: opinions, attitudes and practices to screening for oral mucosal lesions and to counselling patients on tobacco and alcohol use: baseline data from 1991. Oral Dis 1999; 5: 10-14.

7. McLeod N M H, Saeed N R, Ali E A. Oral cancer: delays in referral and diagnosis persist. Br Dent 2005; 198: 681-684

8. Reibel J. Prognosis of oral pre-malignant lesions: significance of clinical, histopathological, and molecular biological characteristics. Crit Rev Oral Biol Med 2003; 14: 47-62.

9. Ryan $M, S$ cott D A, Reeves $C$ et al. Eliciting public preferences for healthcare: a systematic review of techniques. Health Technol Assess 2001; 5(5): 1-186.

10. Scott SE, Grunfeld E A, Main J, McGurk M. Patient delay in oral cancer: a qualitative study of patients experiences. Psychooncology 2006; 15: 474-485.

11. Smith J A. Qualitative psychology. A practical guide to research methods. 2nd ed. pp 4-25. London: Sage Publications, 2008.

12. Willig C. Introducing qualitative research in psychology. Adventures in theory and method. 1st ed. pp 1-30. Maidenhead: Open University Press, 2001.

13. Cresswell J W, Fetters M D, Ivankova N V. Designing a mixed methods study in primary care. Ann Fam Med 2004; 2: 7-12.

14. Braun V, Clarke V. Using thematic analysis in psychology. Qual Res Psychol 2006; 3: 77-101.

15. Holmes J D, Dierks E J, Homer L D, Potter B E. Is detection of oral and oropharyngeal squamous cancer by a dental health care provider associated with a lower stage at diagnosis? J Oral Maxillofac Surg 2003; 61: 285-291.

16. Onizawa K, Nishihara K, Yamagata K et al. Factors associated with diagnostic delay of oral squamous cell carcinoma. Oral Oncol 2003; 39: 781-788.

17. Pitiphat $W$, Diehi $S R$, Laskaris $G$ et al. Factors associated with the delay in the diagnosis of oral cancer. J Dent Res 2002; 81: 192-197.

18. Hollows P, McAndrew P G, Perini M G. Delays in the referral and treatment of oral squamous cell carcinoma. Br Dent J 2000; 188: 262-265.

19. Schnetler J F C. Oral cancer diagnosis and delays in referral. Br J Oral Maxillofac Surg 1992; 30: $210-213$

20. Scully C, Malamos D, Levers B G, Porter S R, Prime $S S$. Sources and patterns of referrals of oral cancer: role of general practitioners. Br Med J (Clin Res Ed) 1986; 293: 599-601.

21. Shafer W G. Initial mismanagement and delay in diagnosis of oral cancer. J Am Dent Assoc 1975: 90: 1262-1264.

22. Brocklehurst $P R$, Baker S R, Speight P M. Factors affecting the referral of potentially malignant lesions from primary dental care: a pilot study in South Yorkshire. Primary Dent Care 2009; 16: 13-18.

23. Carter $S$, Henderson L. Approaches to qualitative data collection in social science. In Bowling A Ebrahim S (eds) Handbook of health research methods. Investigation, measurement and analysis. 1st ed. pp 215-229. Maidenhead: Open University Press, 2007.

24. Napier S, Speight P M. Natural history of potentially malignant oral lesions and conditions: an overview of the literature. J Oral Pathol Med 2008; 37: 1-10.

25. Baker S R. Testing a conceptual model of oral health: a structural equation modelling approach. J Dent Res 2007; 86: 708-712

26. Brocklehurst $P R$, Baker $S R$, Speight $P M$. A qualitative study examining the experience of primary care dentists in the detection and management of potentially malignant lesions. 2. Mechanics of the referral and patient communication. Br Dent J 2010; 208: E4.

27. Brocklehurst PR, Baker S R, Speight P M. Dentists' relationships with other professionals when referring potentially malignant lesions. J Dent Res 2009; 88(Spec Iss B): Abs no. 82 (BSDR). http://iadr.confex com/iadr/bsdr09/webprogram/Paper124648.html.

28. Speight P M, Downer M C, Zakrzewska J (eds). Screening for oral cancer and precancer. A report of the UK Working Group on screening for oral cancer and precancer. Community Dent Health 1993; 10(Suppl 1): 1-89

29. Greenwood M, Lowry R J. Primary care clinicians' knowledge of oral cancer: a study of dentists and doctors in the North East of England. Br Dent J 2001; 191: 510-512.

30. Kay E J, Nuttall N M. Clinical decision making: an art or a science? 1st ed. London: BDJ Books, 2001.

31. National Collaborating Centre for Primary Care. Referral guidelines for suspected cancer. London: National Institute for Heath and Clinical Excellence, 2005.

32. Jaber M A, Porter S R, Speight P M, Eveson J W, Scully C. Oral epithelial dysplasia: clinical characteristics of western European residents. Oral Oncol 2003; 39: 589-596. 